\title{
Experimental results of a national technical assessment procedure on commercial FRP for structural strengthening: wet-lay-up systems
}

\author{
A. Occhiuzzi - F. Ceroni $\cdot$ A. Franco $\cdot$ P. Salzano $\cdot$ A. Bonati
}

Received: 4 June 2019/Accepted: 7 January 2020/Published online: 14 January 2020

(C) The Author(s) 2020

\begin{abstract}
The paper shows the results of a large experimental activity for the qualification of wet-layup FRP products for structural repair and/or strengthening, required by the Italian national approval authority. The qualification procedure and the correspondent design rules are described in national guidelines. The analysis of the experimental results of a large number of qualification tests allows to highlight some aspects in the national procedure that could be addressed in a future revision of the guidelines. In particular, statistical analyses were carried out in order to assess the most suitable probabilistic models able to describe the experimental distribution of the tensile strength and the Young's modulus of FRP wet-lay-up materials falling in the same class. The analyses were developed with reference to both ordinary and artificial environmental conditions. Nevertheless the paper is focussed on the
\end{abstract}

Electronic supplementary material The online version of this article (https://doi.org/10.1617/s11527-020-1439-5) contains supplementary material, which is available to authorized users.

A. Occhiuzzi - A. Franco - A. Bonati

Construction Technologies Institute, Italian National

Research Council, Rome, Italy

A. Occhiuzzi · F. Ceroni · P. Salzano ( $\square)$

Department of Engineering, University of Naples

"Parthenope", Naples, Italy

e-mail: piera.salzano@uniparthenope.it case of wet-lay-up FRP materials, it can be considered exemplary of a problem common to other products.

Keywords FRP wet-lay-up systems · Tensile strength · Young's modulus · Probabilistic models

\section{Introduction}

Due to the huge retrofitting activity following the seismic events that struck Italy in the last decades and especially after L'Aquila earthquake of 2009, Fibre Reinforced Polymers (FRP), in the form of externally bonded systems, have been extensively adopted in Italy for strengthening and repairing damaged structures. FRPs have therefore left their market niche on the Italian scenario of structural strengthening to become a widely adopted system by professionals and construction companies. Guidelines for the design of strengthening interventions on concrete and masonry elements with FRP materials are available since several years in Italy [1-3] and are based on the wide experimental, theoretical and analytical studies carried out by several researchers in the last decades [4-9] focussed on several aspects governing the design (i.e., bond behaviour, flexural and shear strength, confinement, strengthening of beams-columns joints, serviceability conditions).

In addition to the Guidelines for design [1], the Italian Ministry of Infrastructure and Transportation 
published Guidelines [10] on the qualification of such products in 2015 , which were enforced by the end of 2016 and were recently reviewed and published again in 2019. As a result, any FRP manufacturer interested to put its products in the Italian market had to apply to the Ministry for the corresponding qualification, demonstrating the outcomes of the necessary testing activity. A 1st wave of the qualification process, through a joint effort between the "Servizio Tecnico Centrale" (Central Technical Service of the Ministry) and ITC CNR (the Construction Technologies Institute of the Italian National Research Council), was concluded by the end of 2017. To the authors' knowledge, this is the largest single testing campaign on FRP systems, whose results, partially summarized in the following, give some insight on both the mechanical properties of commercial FRPs for construction and the effectiveness of the Italian guidelines.

It is interesting to note that the qualification process prescribes tests under artificial ageing too in order to check the durability of FRP materials. Such an aspect is worth of investigation in order to assess the real strength capacity for FRP applications on both concrete and masonry elements under environmental conditions different from the standard ones [11-14].

The paper is aimed to provide a contribution to current developments at European level in terms of technical assessment procedures for material properties. Nevertheless the paper is focussed on a specific case regarding FRP materials, it can be considered exemplary of a problem that exists in many other cases. Design approaches and reduction factors for special effects are, indeed, often set on basis of a small amount of data and a limited experience may lead to misperceptions. Graduation of products into classes is favoured in the course of European standardization and the possibility of analysing experimental results of a large number of qualification tests would allow to identify the classes more reliably. The experimental results herein examined highlight some aspects in the national procedure that could be addressed in a further revision of the current guidelines [10].

\section{Testing activity}

The Italian Guidelines for the design of structural strengthening through FRP systems [1] are mainly based on the first version of the document issued by the Italian National Research Council published in 2004 [2], which was reviewed in 2013 [3]. In all documents different provisions are made for preformed and cured-in situ (or wet-lay-up) systems. The first typology consists of fibres which have been impregnated with resins in sheet form, characterized by an initial axial stiffness and a generally unidirectional behaviour. They can be manufactured by pultrusion or lamination processes in different shapes and thicknesses, in order to be bonded to structural elements through an epoxy adhesive.

The wet-lay-up systems comprise a wider range of products. They are usually made of dry or lightly impregnated fabrics, to be finally impregnated in situ concurrently to the gluing phase. For the cured-in situ systems, the fabrics available on the market are made of both unidirectional and multi-directional fibres leading to a variable density of the overall mesh. Moreover, wet-lay-up systems can rely on different fibre materials, whereas preformed elements are typically made up of carbon, glass or basalt. According to the Guidelines [10], the testing results in terms of mean value of Young's elastic modulus $E$ and characteristic value (5th percentile) of tensile strength $f_{\text {tk }}$ allow to place a given product in a certain class. Classes provided by the most recent version of [10] are described in Table 1. It is worth noting that some modifications in labels of classes and types of classified products were introduced in the version published in 2019 in comparison with the original one of 2015.

For fabrics made of multidirectional fibres, the values listed in Table 1 have to be referred to the main direction. Furthermore, the FRP systems' environmental durability should also be checked. In particular, strength to freeze/thaw cycles, humidity, saltwater and alkaline environment needs to be investigated with further tensile tests.

The number of cured-in situ and preformed products qualified in the 1st wave are listed in Table 2 and are all characterized by carbon fibres. Note that the experimental tests were carried out before the new version of Guidelines [10] were published, basing, thus, on the classification given by the previous version, but for products made of carbon fibres no changes were done and both classes and labels were the same. 
Table 1 Classes for preformed and cured-in situ FRP systems given by Italian Guidelines [10]

\begin{tabular}{|c|c|c|c|c|c|c|c|}
\hline \multicolumn{4}{|c|}{ Preformed FRP systems } & \multicolumn{4}{|c|}{ Cured-in situ FRP systems } \\
\hline Class & Type of fibres & $E(\mathrm{GPa})$ & $f_{\mathrm{tk}}(\mathrm{MPa})$ & Class & Type of fibres & $E(\mathrm{GPa})$ & $f_{\text {tk }}(\mathrm{MPa})$ \\
\hline E17/B17 & \multirow[t]{7}{*}{ Glass/Basalt } & 17 & 170 & $60 \mathrm{G} / 60 \mathrm{~B}$ & Glass/Basalt & 60 & 1300 \\
\hline E23/B23 & & 23 & 240 & $210 \mathrm{C}$ & \multirow[t]{6}{*}{ Carbon } & 210 & 2700 \\
\hline G38/600 & & 38 & 600 & $350 / 1750 \mathrm{C}$ & & 350 & 1750 \\
\hline \multicolumn{6}{|l|}{ B38/600 } & & \\
\hline G38/800 & & 38 & 800 & $350 / 2800 \mathrm{C}$ & & 350 & 2800 \\
\hline \multicolumn{6}{|l|}{ G38/600 } & & \\
\hline G45/B45 & & 45 & 1000 & $500 \mathrm{C}$ & & 500 & 2000 \\
\hline $\mathrm{C} 120$ & \multirow[t]{5}{*}{ Carbon } & 120 & 1800 & $100 \mathrm{~A}$ & Aramid & 100 & 2200 \\
\hline $\mathrm{C} 150 / 1800$ & & 150 & 1800 & $180 \mathrm{~S}$ & \multirow{5}{*}{$\begin{array}{l}\text { UHTSS (ultra high } \\
\text { tensile strength) steel }\end{array}$} & 180 & 2200 \\
\hline $\mathrm{C} 150 / 2300$ & & 150 & 2300 & $190 \mathrm{~S}$ & & 190 & 2200 \\
\hline C190/1800 & & 190 & 1800 & & & & \\
\hline C200/1800 & & 200 & 1800 & & & & \\
\hline A55 & Aramid & 55 & 1200 & & & & \\
\hline
\end{tabular}

Table 2 Mechanical characterization of cured-in situ and preformed FRP products and number of single tests

\begin{tabular}{|c|c|c|c|c|c|c|c|}
\hline \multicolumn{5}{|c|}{ Cured-in situ FRP products } & \multicolumn{3}{|c|}{ Preformed FRP products } \\
\hline \multirow[t]{2}{*}{ Class } & \multicolumn{2}{|l|}{1 layer } & \multicolumn{2}{|l|}{3 layers } & \multirow[t]{2}{*}{ Class } & \multirow{2}{*}{$\begin{array}{l}\text { No. } \\
\text { products }\end{array}$} & \multirow{2}{*}{$\begin{array}{l}\text { No. of } \\
\text { single tests }\end{array}$} \\
\hline & No. products & No. of single tests & No. products & No. of single tests & & & \\
\hline $210 \mathrm{C}$ & 30 & 270 & 32 & 288 & $\mathrm{C} 150 / 1800$ & 1 & 15 \\
\hline $350 / 1750 \mathrm{C}$ & 3 & 27 & 2 & 18 & $\mathrm{C} 150 / 2300$ & 5 & 75 \\
\hline $350 / 2800 \mathrm{C}$ & 8 & 72 & 9 & 81 & C190/1800 & 2 & 30 \\
\hline \multirow[t]{2}{*}{ Total } & 41 & 369 & 43 & 387 & C200/1800 & 3 & 45 \\
\hline & & & & & Total & 11 & 165 \\
\hline
\end{tabular}

The number of single tensile tests required by [10] is 15 for preformed products. Conversely, for the classification of cured-in situ systems, the tensile tests must be performed on two sets of 9 specimens each. The first set (Group A) is made of three overlapped layers of the same fabric, while the second one (Group $\mathrm{B}$ ) is made of a number of layers considered relevant by the manufacturer. Almost all manufacturers chose to test 1-ply specimens in group B.

Experimental data belonging to the more populated class of cured-in situ products, namely 210C, have been analysed and results are described in the following, whereas preformed systems will be dealt with in a separate article [15]. Data come from 8 different laboratories, all of them located in Italian Universities. Specimens are characterized by a width in the range from 40 to $70 \mathrm{~mm}$ and a length from 250 to $350 \mathrm{~mm}$ (grips excluded). The recommended speed for the tensile tests is between 0.5 and $2.0 \mathrm{~mm} / \mathrm{min}$.

\section{Analysis of experimental data: wet-lay-up systems}

For the wet-lay-up (cured-in situ) FRP systems, the most numerous class is composed of 30 carbon fibre products that fall within the $210 \mathrm{C}$ class. 270 experimental pairs of values ( $E$ and $f_{\mathrm{t}}$ ) are available for 1-ply specimens, whereas 288 couples are the results measured on 3-ply specimens.

As for 1-layer specimens, experimental data were utilized to construct recurrence normalized 
histograms, where bins are $10 \mathrm{GPa}$ wide for $E$ and $200 \mathrm{MPa}$ wide for $f_{\mathrm{t}}$ (Figs. 1a, 2a, respectively). Accordingly, the Empirical Cumulative Density Function (ECDF) was calculated and plotted in Figs. 1b and $2 \mathrm{~b}$ for $E$ and $f_{t}$, respectively.

As it is clear from figures, the experimental data are more concentrated around values lightly greater than the threshold values of $210 \mathrm{GPa}$ for the elastic modulus and $2700 \mathrm{MPa}$ for the tensile strength and yield non-symmetric distributions of the data. The average experimental values are, indeed, $256 \mathrm{GPa}$ and $3693 \mathrm{GPa}$ for $E$ and $f_{t}$, respectively.

Therefore, data fitting considered the following analytical distributions (i.e., Probability Density Function, PDF): Lognormal, 3-parameter Lognormal and 3-parameter Weibull [16-21]. Such distributions are also plotted in Figs. 1 and 2, for comparison with experimental data in terms of both PDF and CDF. The Weibull distribution [16] is often used to describe the strength of fibres [17, 18] and FRP composites [19-21].

The standard lognormal distribution requires the computation of the parameters $\mu$ and $\sigma^{2}$. The threeparameters lognormal distribution needs, in addition, the prior determination of the threshold parameter $\theta$ (or location parameter) that defines the point where the support set of the distribution begins. The latter can be easily found through a Maximum Likelihood Estimate (MLE).

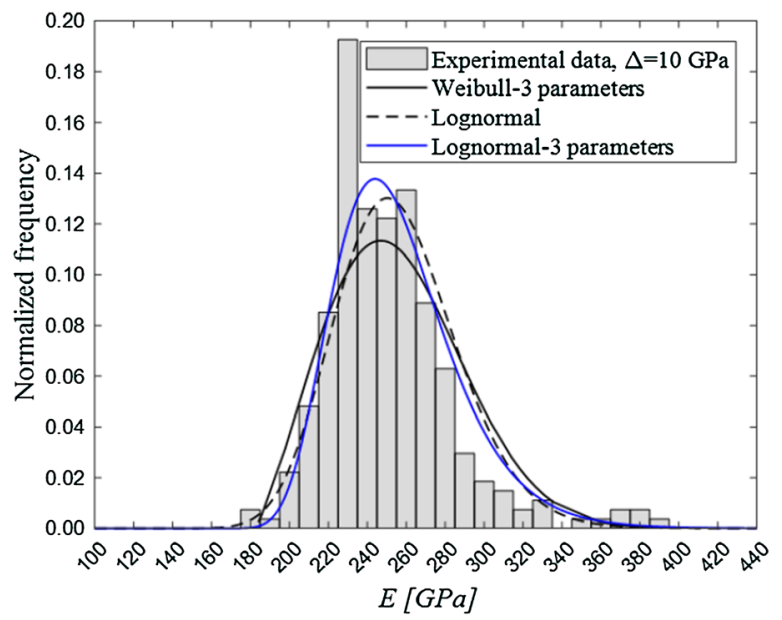

(a)
The Weibull distribution is described by the scale $(\lambda)$, shape $(k)$, and threshold $(\theta)$ parameters. The case when the threshold parameter is zero is called the 2-parameter Weibull distribution. For our purposes, the software SPC for excel [22] has been used for computing the parameters associated with the probability law from the experimental data. This software performs a best-fit parameter estimation through the Maximum Likelihood Estimate (MLE) method.

Table 3 shows the value of the parameters adopted for the data fitting.

The three probability models are superimposed on the experimental data in Figs. 1 and 2. In order to have a quantitative estimate of the fitting goodness for a distribution whose parameters have been estimated from the sample, the Kolmogorov-Smirnov (K-S) test has been considered. This test is an effective tool that allows to compare different distributions and choose the best fit for data representation. The test is based on the comparison between the maximum absolute difference between the Cumulative Distribution Function related to the experimental data, ECDF, and the one associated with each probability distributions; this difference is computed as follows:

$D_{\mathrm{MAX}}=\max \{|F(x)-\varphi(x)|\}$

where $F(x)$ is the ECDF of the sample, whereas $\varphi(x)$ is the CDF of the examined probability distribution.

The hypothesis regarding the distributional form is rejected if $D_{\text {MAX }}$ is greater than a certain critical value,

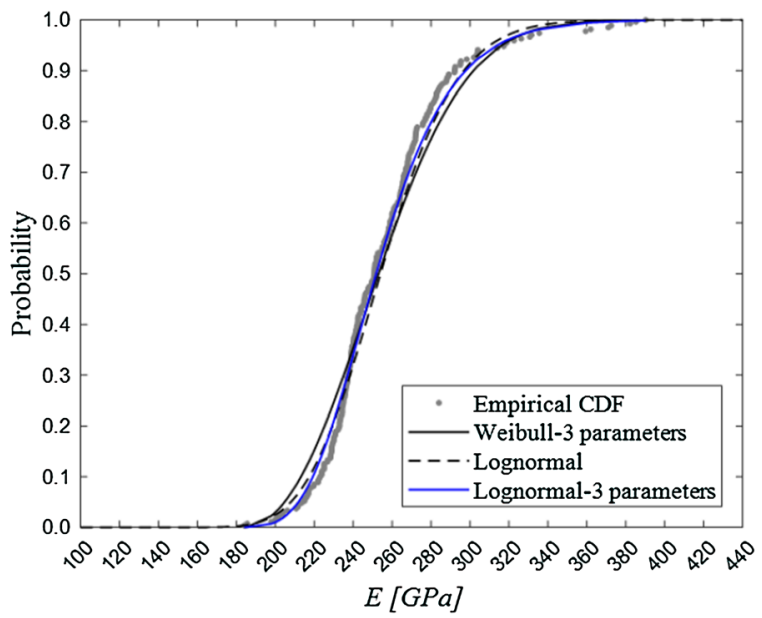

(b)

Fig. 1 Distribution fitting for 1-layer cured-in situ FRP systems (class 210C): comparison between a empirical histograms and PDF and $\mathbf{b}$ Empirical and theoretical CDF of the considered probabilistic distribution of $E$ 


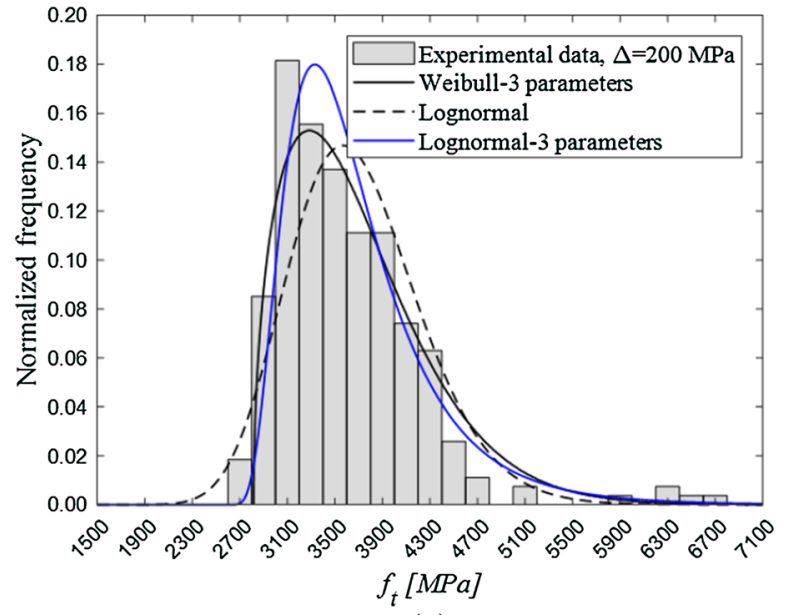

(a)

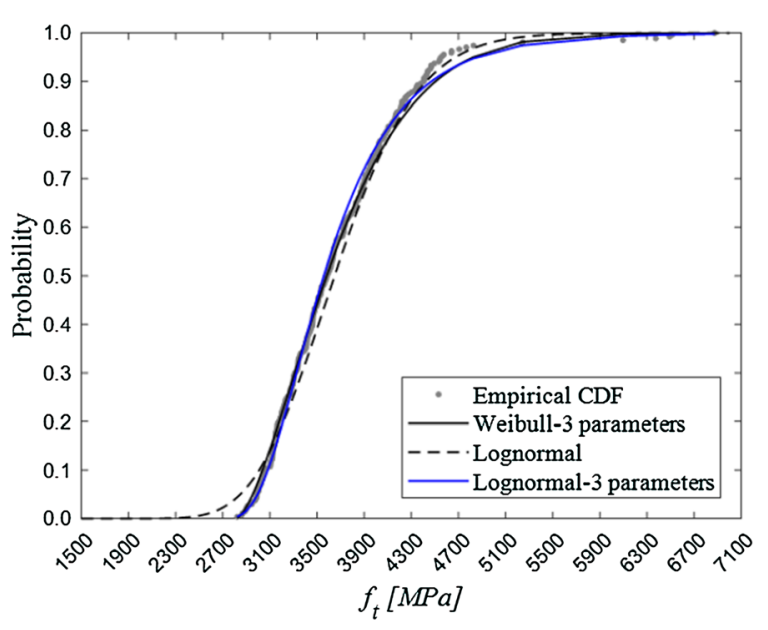

(b)

Fig. 2 Distribution fitting for 1-layer cured-in situ FRP systems (class 210C): comparison between a empirical histograms and PDF and $\mathbf{b}$ Empirical and theoretical CDF of the considered probabilistic distribution of $f_{\mathrm{t}}$

Table 3 Parameters of probability models: 1-layer cured-in situ FRP systems (class 210C)

\begin{tabular}{lllll}
\hline Probability distributions & Variable & \multicolumn{2}{l}{ Values of fitting parameters } & \\
\hline Lognormal & $E$ & $\mu=5.54$ & $\sigma=0.12$ & \\
& $f_{\mathrm{t}}$ & $\mu=8.20$ & $\sigma=0.15$ & \\
3-p Lognormal & $E$ & $\mu=4.72$ & $\sigma=0.27$ & $\theta=140.1$ \\
& $f_{\mathrm{t}}$ & $\mu=6.90$ & $\sigma=0.51$ & $\theta=2565$ \\
3-p Weibull & $E$ & $\lambda=85.3$ & $k=2.30$ & $\theta=181.8$ \\
& $f_{\mathrm{t}}$ & $\lambda=974$ & $k=1.50$ & $\theta=2816$ \\
\hline
\end{tabular}

that depends on the sample size, $N$, and the level of significance, $\alpha$, of the test. There are several tables available in literature, for our purpose we will refer to the Massey [23] and Lilliefors [24] critical values.

Typically, the Kolmogorov-Smirnov test is executed with a level of significance of 0.05 , which means that one is willing to accept the fact that in $5 \%$ of samples the null hypothesis (the estimate of the difference between the experimental and the theoretical CDF is based solely on chance) is rejected.

In order to have a quantitative evaluation of the goodness of fit, Kolmogorov-Smirnov tests have been conducted, comparing the maximum differences obtained with the critical values.

Results reported in Table 4 show that for both elastic modulus and tensile strength, the $D_{\mathrm{MAX}}$ obtained for the Lognormal and 3-p Lognormal distributions do not reject the null hypothesis for all significant levels and critical values provided by
Massey [23] (values of $D_{\mathrm{MAX}}$ lower than the critical value are those which satisfy the $\mathrm{K}-\mathrm{S}$ test). The 3-p Weibull distribution also turns out to be appropriate for the representation of tensile strength, with a minor accuracy for the elastic modulus. Lilliefors [24], on the other hand, provides more restrictive critical values that in some cases confirm the Massey's outcomes. The 3-p Lognormal appears to be the distribution that best fits the experimental data. However, any of the considered distributions appears to be fairly adequate to describe the experimental data.

In the case of three-layers cured-in situ FRP products, the distribution fitting analysis has also been conducted for both Young's elastic modulus and tensile strength of the tested systems. The results are reported in ESM Appendix A, where bins are $10 \mathrm{GPa}$ wide for $E$ and $150 \mathrm{MPa}$ wide for $f_{t}$. Accordingly, the Empirical CDF was also calculated and plotted in ESM Appendix A. Also in the cases of tests on threelayers specimens, the mean values of $E$ and $f_{t}$ are 
Table $4 \mathrm{~K}-\mathrm{S}$ test for elastic modulus $E$ and tensile strength $f_{t}$ of cured-in situ 1-layer products

\begin{tabular}{|c|c|c|c|c|c|c|c|c|}
\hline \multirow[t]{2}{*}{$\mathrm{K}-\mathrm{S}$ test } & \multirow[t]{2}{*}{ Distribution } & \multirow[t]{2}{*}{$D_{\text {MAX }}$} & \multicolumn{3}{|c|}{ Critical values (Massey, 1951) } & \multicolumn{3}{|c|}{ Critical values (Lilliefors, 1967) } \\
\hline & & & $\alpha=0.10$ & $\alpha=0.05$ & $\alpha=0.01$ & $\alpha=0.10$ & $\alpha=0.05$ & $\alpha=0.01$ \\
\hline \multirow[t]{3}{*}{ Elastic modulus $E$} & Lognormal & 0.066 & 0.070 & 0.078 & 0.093 & 0.046 & 0.051 & 0.059 \\
\hline & 3-p Lognormal & 0.052 & & & & & & \\
\hline & 3-p Weibull & 0.092 & & & & & & \\
\hline \multirow[t]{3}{*}{ Tensile strength $f_{t}$} & Lognormal & 0.061 & & & & & & \\
\hline & 3-p Lognormal & 0.043 & & & & & & \\
\hline & 3-p Weibull & 0.044 & & & & & & \\
\hline
\end{tabular}

higher than the threshold ones (i.e., $262 \mathrm{GPa}$ and $3658 \mathrm{MPa}$, respectively).

Data fitting was done considering again Lognormal, 3-p Lognormal, and 3-p Weibull distributions by adopting the parameters shown in Table 5. However, a good fit for the data regarding $f_{t}$ could not be found with a 3-p Weibull distribution.

The probability models are superimposed on the experimental data in Figs. 1 and 2 of ESM Appendix in terms of both PDF and CDF. In order to have a quantitative estimate of the fitting goodness for a distribution whose parameters have been estimated from the sample, the Kolmogorov-Smirnov (K-S) test has been considered again, as shown in Table 6. For 3-layer specimens, the Lognormal and 3-p Lognormal yield the same accuracy in fitting the experimental data.

Table 7 summarizes the mean value of the Young's modulus $E$, the lower $5 \%$ fractile and the mean value of the tensile strength, respectively $f_{\mathrm{t} 5}$ and $f_{\mathrm{tm}}$, according to the empirical data and the analytical representations adopted for both tests on 1-ply and 3-ply specimens.

Differences in statistical descriptions of experimental data of 1-ply and 3-ply specimens hardly justify the need for a double series of tests, as prescribed in [10]. Differences are, indeed, very light (less than 1\%). Furthermore, results corresponding to the three considered distributions are relatively close for practical applications. Thus, only the 3-p Lognormal fitting will be considered in the following analyses.

\section{Effect of artificial ageing}

According to the Italian Guidelines [10], the FRP systems' environmental durability should also be checked. In particular, strength to freeze/thaw cycles, humidity, saltwater and alkaline environment needs to be investigated with further tensile tests.

For the strength to freeze/thaw cycles, the conditioning procedure requires specimens to be placed in environments characterized by relative humidity $\mathrm{RH}$ $\geq 90 \%$ and temperature $T=38 \pm 2{ }^{\circ} \mathrm{C}$ for 7 days, then 20 freeze/thaw cycles are to be performed. Each cycle consists of $4 \mathrm{~h}$ at a $-18 \pm 1{ }^{\circ} \mathrm{C}$, followed by $12 \mathrm{~h}$ at $\mathrm{RH} \geq 90 \%$ and $T=38 \pm 2{ }^{\circ} \mathrm{C}$. After the 20 cycles, samples are visually examined to describe surface changes, after which tensile tests can be
Table 5 Parameters of probability models 3-layers cured-in situ FRP systems (class 210C)

\begin{tabular}{lllll}
\hline Probability distributions & Variable & Values of fitting parameters & \\
\hline Lognormal & $E$ & $\mu=5.54$ & $\sigma=0.12$ & \\
& $f_{t}$ & $\mu=8.19$ & $\sigma=0.14$ & \\
3-p Lognormal & $E$ & $\mu=4.43$ & $\sigma=0.36$ & $\theta=166.3$ \\
& $f_{t}$ & $\mu=7.12$ & $\sigma=0.39$ & $\theta=2319$ \\
3-p Weibull & $E$ & $\lambda=66.2$ & $k=1.90$ & $\theta=196.9$ \\
& $f_{t}$ & $k=-$ & $\lambda=-$ & $\theta=-$ \\
\hline
\end{tabular}


Table $6 \mathrm{~K}-\mathrm{S}$ test for elastic modulus $E$ and tensile strength $f_{t}$ of cured-in situ 3-layer products

\begin{tabular}{|c|c|c|c|c|c|c|c|c|}
\hline \multirow[t]{2}{*}{$\mathrm{K}-\mathrm{S}$ test } & \multirow[t]{2}{*}{ Distribution } & \multirow[t]{2}{*}{$D_{\text {MAX }}$} & \multicolumn{3}{|c|}{ Critical values (Massey, 1951) } & \multicolumn{3}{|c|}{ Critical values (Lilliefors, 1967) } \\
\hline & & & $\alpha=0.10$ & $\alpha=0.05$ & $\alpha=0.01$ & $\alpha=0.10$ & $\alpha=0.05$ & $\alpha=0.01$ \\
\hline \multirow[t]{3}{*}{ Elastic modulus $E$} & Lognormal & 0.059 & 0.070 & 0.078 & 0.093 & 0.046 & 0.051 & 0.059 \\
\hline & 3-p Lognormal & 0.059 & & & & & & \\
\hline & 3-p Weibull & 0.064 & & & & & & \\
\hline \multirow[t]{2}{*}{ Tensile strength $f_{t}$} & Lognormal & 0.058 & & & & & & \\
\hline & 3-p Lognormal & 0.058 & & & & & & \\
\hline
\end{tabular}

Table 7 Mechanical parameters of $210 \mathrm{C}$ products

\begin{tabular}{lll}
\hline & 1-ply specimens & 3-ply specimens \\
\hline$E$ (GPa) & & \\
Empirical & 256 & 256 \\
Lognormal & 257 & 257 \\
3-p Lognormal & 256 & 256 \\
3-p Weibull & 257 & 256 \\
$f_{\text {tm }}$ (MPa) & & \\
Empirical & 3693 & 3658 \\
Lognormal & 3682 & 3640 \\
3-p Lognormal & 3695 & 3653 \\
3-p Weibull & 3695 & - \\
$f_{\text {t5 }}$ (MPa) & & \\
Empirical & 2988 & 2970 \\
Lognormal & 2843 & 2861 \\
3-p Lognormal & 2993 & 2969 \\
3-p Weibull & 2950 & - \\
\hline
\end{tabular}

carried out. The test success is determined by comparing the average values of Young's modulus and strength ( $E$ and $f_{\mathrm{t}}$ ) of the conditioned samples with a certain percentage (function of the conditioning duration) of the average values of the unconditioned samples.

For the artificial ageing, the conditioning procedures are the following ones:

(a) Curing at $\mathrm{RH} \geq 90 \%$ and $T=38 \pm 2{ }^{\circ} \mathrm{C}$ for 1000 or $3000 \mathrm{~h}$ (water resistance according to ASTM D 2247-11 and ASTM E 104-02);

(b) Immersion in saltwater at $23 \pm 2{ }^{\circ} \mathrm{C}$ for 1000 or $3000 \mathrm{~h}$ (saltwater resistance according to ASTM D 1141-98 and ASTM C 581-03); (c) Immersion in aqueous solution with $\mathrm{pH}=12$ and $T=23 \pm 2{ }^{\circ} \mathrm{C}$ for 1000 or $3000 \mathrm{~h}$ (strength to alkaline environment, according to ASTM D7705/D7705M).

If average values of $E$ and $f_{\mathrm{t}}$ measured on samples conditioned for $1000 \mathrm{~h}$ are higher than $85 \%$ (80\% in case of $3000 \mathrm{~h}$ ) of the average values of the not conditioned samples, the test is considered positive.

It is worth noting that for each conditioning procedure, four conditioned and four unconditioned specimens are involved; the unconditioned specimens are extracted from the same batch but do not correspond to the ones involved in the mechanical characterization. Moreover, for the cured-in situ FRP systems, tests under artificial environmental conditions must be performed on specimens made of three layers. Experimental data confirmed that the statistical description of the results on unconditioned specimens tested to compare ageing effects does not significantly differ from the analytical representation of the population made of the original 288 samples.

Artificial ageing effects are summarized in the following section. In all cases, $10 \mathrm{GPa}$ wide bins for $E$ and $150 \mathrm{MPa}$ wide bins for $f_{\mathrm{t}}$ have been adopted.

\subsection{Discussion on artificial ageing effects}

The experimental data and the analytical interpretation of the 136 specimens exposed to different conditioning procedures, i.e., freeze/thaw cycles, humidity, saltwater and alkaline environment $(1000 \mathrm{~h})$, are reported in ESM Appendix A.

Table 8 shows the parameters adopted for the data fitting of the sets of conditioned specimens, assuming only the 3-p Lognormal law, as discussed in Sect. 3. 
The results of the $\mathrm{K}-\mathrm{S}$ test for all the aforementioned conditioning procedures are summarized in Table 9.

Table 10 summarizes the mean value of the Young's modulus $E$, the 5 th percentile, $f_{\mathrm{t} 5}$, and the mean value, $f_{\mathrm{tm}}$, of tensile strength, according to the empirical data and the analytical representation of the 3-p Lognormal distribution, calculated for the unconditioned and the variously conditioned samples.

Table 11 summarizes average values, standard deviations and coefficients of variation for $E$ and $f_{\mathrm{t}}$ in the case of unconditioned and variously conditioned samples.

The mean value of Young's modulus moderately increases after artificial ageing. For empirical data, the positive variation is in the range from $1.1 \%$ (alkali environment) to $4.2 \%$ (freeze/thaw cycles), except for saltwater conditioning that induced a slight reduction $(-2.3 \%)$. The analytical variations are similar with exception of the freeze/thaw cycles, where it is $18 \%$ against $4.2 \%$. Despite of the low variation of the average values of the Young's modulus, artificial ageing makes the corresponding probabilistic description of the experimental data more scattered compared to unconditioned samples. The coefficient of variation jumps, indeed, from 0.13 to $0.23-0.26$. This means a significant reduction of the 5th percentile of tensile strength associated with all the artificial aged test results, ranging from -26 to $-21 \%$.

For the tensile strength, the average values reduce moderately, i.e., $8-11 \%$, for all the artificial conditionings, but data scattering increases with any of the ageing procedures and the corresponding coefficient of variation jumps, indeed, from 0.15 to $0.20-0.22$. Such an increase of the coefficient of variation leads to sensible variations of the 5 th percentile of the tensile strength that reduces by $21-26 \%$, depending on the artificial ageing.

Finally, it can be concluded that the 3-p Lognormal distribution appears to be a satisfactory descriptor of the test results, with exception of the Young's modulus for freeze/thaw artificial ageing.

In conclusion, ageing effects on the mean value of the Young's modulus of tested products seem to be negligible, whereas a significant reduction of the 5th percentile value of the tensile strength appears a common consequence of all the artificial ageing procedures.

\section{Material partial factors in the Italian standards}

According to the Eurocode 0 [25], the design value of a product property can be expressed as:

$X_{\mathrm{d}}=\eta \frac{X_{\mathrm{k}}}{\gamma_{\mathrm{m}}}$

where $X_{\mathrm{d}}$ is the design value, $X_{\mathrm{k}}$ is the characteristic value (herein the 5th percentile of the probability distribution), $\eta$ is a conversion factor related to environmental conditions and $\gamma_{\mathrm{m}}$ is the material partial factor.

By neglecting in a first stage the conversion factor $(\eta=1)$, the material partial factor can be calculated as:

$\gamma_{\mathrm{m}}=\frac{X_{\mathrm{k}}}{X_{\mathrm{d}}}$

Since the 3-p Lognormal distribution resulted a suitable probability distribution for tensile strength

Table 8 Parameters of probability models: 3-layer 210C products exposed to different conditioning procedures

\begin{tabular}{|c|c|c|c|c|c|}
\hline \multirow{2}{*}{$\begin{array}{l}\text { Conditioning procedure } \\
\text { Exposure to freeze/thaw }\end{array}$} & \multirow{2}{*}{$\frac{\text { Variable }}{E}$} & \multirow{2}{*}{$\frac{\text { Distribution }}{\text { 3-p Lognormal }}$} & \multicolumn{3}{|c|}{ Values of fitting parameters } \\
\hline & & & $\mu=7.3$ & $\sigma=0.05$ & $\theta=-1179.5$ \\
\hline & $f_{\mathrm{t}}$ & & $\mu=8.0$ & $\sigma=0.23$ & $\theta=317.5$ \\
\hline \multirow[t]{2}{*}{ Exposure to humidity } & $E$ & & $\mu=6.58$ & $\sigma=0.09$ & $\theta=-458.07$ \\
\hline & $f_{\mathrm{t}}$ & & $\mu=7.82$ & $\sigma=0.24$ & $\theta=627.82$ \\
\hline \multirow[t]{2}{*}{ Exposure to saltwater } & $E$ & & $\mu=6.93$ & $\sigma=0.06$ & $\theta=-756.6$ \\
\hline & $f_{\mathrm{t}}$ & & $\mu=7.7$ & $\sigma=0.31$ & $\theta=996.41$ \\
\hline \multirow[t]{2}{*}{ Exposure to alkaline environment } & E & & $\mu=6.52$ & $\sigma=0.10$ & $\theta=-418.5$ \\
\hline & $f_{\mathrm{t}}$ & & $\mu=7.74$ & $\sigma=0.28$ & $\theta=936.2$ \\
\hline
\end{tabular}


Table $9 \mathrm{~K}-\mathrm{S}$ test for $E$ and $f_{\mathrm{t}}$ of cured-in situ 3-layer products exposed to different conditioning procedures

\begin{tabular}{|c|c|c|c|c|c|c|c|c|c|}
\hline \multirow[t]{2}{*}{ Conditioning procedure } & \multirow[t]{2}{*}{ Variable } & \multirow[t]{2}{*}{ Distribution } & \multirow[t]{2}{*}{$D_{\text {MAX }}$} & \multicolumn{3}{|c|}{$\begin{array}{l}\text { Critical values (Massey, } \\
\text { 1951) with } \alpha \text { : }\end{array}$} & \multicolumn{3}{|c|}{$\begin{array}{l}\text { Critical values (Lilliefors, } \\
\text { 1967) with } \alpha \text { : }\end{array}$} \\
\hline & & & & 0.10 & 0.05 & 0.01 & 0.10 & 0.05 & 0.01 \\
\hline \multirow[t]{2}{*}{ Exposure to freeze/thaw } & $E$ & 3-p Lognormal & 0.093 & 0.096 & 0.108 & 0.129 & 0.064 & 0.070 & 0.082 \\
\hline & $f_{\mathrm{t}}$ & & 0.061 & & & & & & \\
\hline \multirow[t]{2}{*}{ Exposure to humidity } & $E$ & & 0.114 & & & & & & \\
\hline & $f_{\mathrm{t}}$ & & 0.063 & & & & & & \\
\hline \multirow[t]{2}{*}{ Exposure to saltwater } & $E$ & & 0.127 & & & & & & \\
\hline & $f_{\mathrm{t}}$ & & 0.073 & & & & & & \\
\hline \multirow[t]{2}{*}{ Exposure to alkaline environment } & $E$ & & 0.121 & & & & & & \\
\hline & $f_{\mathrm{t}}$ & & 0.059 & & & & & & \\
\hline
\end{tabular}

Table 10 Mechanical parameters of 3-ply 210C products: unconditioned and variously conditioned specimens

\begin{tabular}{|c|c|c|c|c|c|c|c|c|c|}
\hline$E(\mathrm{GPa})$ & Unconditioned & \multicolumn{2}{|c|}{ Freeze/thaw } & \multicolumn{2}{|c|}{ Humidity } & \multicolumn{2}{|c|}{ Saltwater } & \multicolumn{2}{|c|}{ Alkali envir. } \\
\hline Empirical & 262 & 273 & $(+4.2 \%)$ & 267 & $(+1.9 \%)$ & 268 & $(-2.3 \%)$ & 265 & $(+1.1 \%)$ \\
\hline Analytical & 256 & 303 & $(+18 \%)$ & 265 & $(+3.5 \%)$ & 268 & $(+4.7 \%)$ & 263 & $(+2.7 \%)$ \\
\hline \multicolumn{10}{|l|}{$f_{\mathrm{tm}}(\mathrm{MPa})$} \\
\hline Empirical & 3658 & 3374 & $(-7.8 \%)$ & 3250 & $(-11 \%)$ & 3304 & $(-9.7 \%)$ & 3323 & $(-9.2 \%)$ \\
\hline Analytical & 3653 & 3375 & $(-7.6 \%)$ & 3250 & $(-11 \%)$ & 3310 & $(-9.4 \%)$ & 3324 & $(-9.0 \%)$ \\
\hline \multicolumn{10}{|l|}{$f_{\mathrm{t} 5}(\mathrm{MPa})$} \\
\hline Empirical & 2970 & 2208 & $(-26 \%)$ & 2293 & $(-23 \%)$ & 2218 & $(-25 \%)$ & 2331 & $(-21 \%)$ \\
\hline Analytical & 2969 & 2359 & $(-21 \%)$ & 2306 & $(-22 \%)$ & 2323 & $(-22 \%)$ & 2386 & $(-20 \%)$ \\
\hline
\end{tabular}

Table 11 Statistical description of tests on 3-ply $210 \mathrm{C}$ products: unconditioned and variously conditioned specimens

\begin{tabular}{llllll}
\hline & Unconditioned & Freeze/thaw & Humidity & Saltwater & Alkali envir. \\
\hline$E(\mathrm{GPa})$ & & & & & \\
Average & 262 & 303 & 265 & 268 & 263 \\
Standard deviation & 33 & 74 & 65 & 62 & 68 \\
Coeff. of variation & 0.130 & 0.245 & 0.246 & 0.230 & 0.259 \\
$f_{\mathrm{t}}(\mathrm{MPa})$ & & & & & \\
Average & 3653 & 3378 & 3190 & 3313 & 3327 \\
Standard deviation & 541 & 713 & 624 & 736 & 683 \\
Coeff. of variation & 0.148 & 0.211 & 0.196 & 0.222 & 0.205 \\
\hline
\end{tabular}

(see previous sections), the corresponding design value can be expressed as follows:

$$
\begin{aligned}
X_{\mathrm{d}}=\vartheta & +\left(\mu_{\mathrm{m}}-\vartheta\right) \\
& \cdot e^{-\left[\frac{1}{2} \ln \left(1+\frac{\sigma_{\mathrm{m}}^{2}}{\left(\mu_{\mathrm{m}}-\vartheta\right)^{2}}\right)+\alpha_{\mathrm{R}} \cdot \beta \sqrt{\left.\ln \left(1+\frac{\sigma_{\mathrm{m}}^{2}}{\left(\mu_{\mathrm{m}}-\vartheta\right)^{2}}\right)\right]}\right.}
\end{aligned}
$$


where $\mu_{\mathrm{m}}$ is the mean of the probability distribution of the material property; $\sigma_{\mathrm{m}}$ is the standard deviation of the probability distribution of the material property; $\theta$ : is the threshold parameter of the 3-p Lognormal distribution; $\alpha_{\mathrm{R}}$ : is the FORM (First Order Reliability Method) sensitivity factor; $\beta$ is the target reliability index.

According to the 3-p Lognormal analysis, the characteristic value of the tensile strength of the tested population is $f_{\mathrm{tk}}=2969 \mathrm{MPa}$, the mean value is $f_{\mathrm{tm}}=3653 \mathrm{MPa}$, and the standard deviation is $541 \mathrm{MPa}$ (see Table 7). It is worth noting that the characteristic value equals the mean value minus 1.263 times the standard deviation. The acceptance criteria described in the Italian Guidelines [10] assume the characteristic tensile strength equal to the mean value minus 2 times the standard deviation. Consequently, the corresponding value of the characteristic tensile strength is underestimated by [10].

By assuming a value of 0.8 for the FORM sensitivity factor $\alpha_{\mathrm{R}}$ and a value of 3.8 for the target reliability index $\beta$ (Consequences Class CC2, Reliability Class RC2, 50 years return period according to EN 1990 [25], the design value can be calculated as:

$$
\begin{aligned}
f_{\mathrm{td}}= & \vartheta+\left(\mu_{\mathrm{f}}-\vartheta\right) \cdot e^{-\left[\frac{1}{2} \ln \left(1+\frac{\sigma_{\mathrm{f}}^{2}}{\left(\mu_{\mathrm{f}}-\vartheta\right)^{2}}\right)+\alpha_{\mathrm{R}} \cdot \beta \sqrt{\left.\ln \left(1+\frac{\sigma_{\mathrm{f}}^{2}}{\left(\mu_{\mathrm{f}}-\vartheta\right)^{2}}\right)\right]}\right.}=2,319+(3,653-2,319) \\
& \cdot e^{-\left[\frac{1}{2} \ln \left(1+\frac{541^{2}}{(3,653-2,319)^{2}}\right)+0.8 \cdot 3.8 \sqrt{\left.\ln \left(1+\frac{541^{2}}{(3,653-2,319)^{2}}\right)\right]}\right.} \\
= & 2,697 \mathrm{MPa}
\end{aligned}
$$

Thus, the material partial factor of the tested population can be assumed as

$\gamma_{\mathrm{f}}=\frac{f_{\mathrm{tk}}}{f_{\mathrm{td}}}=\frac{2,969}{2,697}=1.10$

The design procedure according to the Italian Guidelines [1] provides two different sets of values for the material partial factor, one dealing with the strength of reinforcing material and the other with the debonding from a substrate. As for the tensile failure for the fibres, a lower value, 1.10, is prescribed for composite kits where both materials and the complete applied system on a definite substrate are fully qualified, whereas an higher value, 1.25, is suggested for composite systems where only materials are qualified. Dealing with the strength, the need of a double partial factor seems to be suitable. In fact, the lowest value, 1.10, exactly coincides with the strength partial factor related to the experimental data presented before, while the highest one, 1.25, leads to a more conservative design in order to take into account uncertainties related to operations on the construction site. It is worth to note that the most recent version of document issued by CNR [3] provides the only value 1.1 as safety factor for the tensile strength of the fibres, being, thus, in agreement with the experimental data herein presented.

Both Guidelines [1] and CNR documents [2, 3] prescribe environmental conversion factors equal to $0.95,0.85$ and 0.85 for, respectively, indoor, outdoor and aggressive environments in the case of carbon fibres. At least for aggressive environments, the 5th percentile values of tensile strength listed in Table 10 due to artificial ageing show that an environmental conversion factor equal to 0.75 should be utilized for carbon fibres in the most common environmental conditionings (freeze/thaw, humidity, saltwater, alkali environmental).

\section{Compliance to classification criteria}

As already said, according to Italian Guidelines [10], FRP materials are divided in several classes. In order to belong to a certain class, the strength characteristic value, $f_{\mathrm{tk}}$, and the mean Young's modulus value, $E$, must be both greater than the nominal values associated with each class. Both values have to be obtained by tensile tests under standard environmental conditions (temperature $T=20{ }^{\circ} \mathrm{C}$, Relative Humidity $\mathrm{RH}=50 \%)$. The characteristic value $f_{\mathrm{tk}}$ is conventionally calculated by subtracting 2 times the standard deviation from the mean value, assuming that the resulting value is roughly equal to the lower 5th percentile. The determination of the FRP system effective class is gained comparing the outcomes obtained from the comparison of both characteristic tensile strength and mean Young's modulus to the nominal values, by choosing the most restrictive class.

As previously discussed, the class $210 \mathrm{C}$ turned out to be the most populated class for cured-in situ FRP systems, which comprises about 30 carbon fibre products, while the total database was composed of 45 carbon fibre products. In ESM Appendix A, the 
average values of Young's modulus, $E_{\mathrm{m}}$, and the characteristic values of the tensile strength, $f_{\mathrm{tk}}$, of each of the 30 products liable to fall in class $210 \mathrm{C}$ are plotted. The values are obtained from tensile tests on specimens made of one layer of CFRP (Carbon Fibre Reinforced Polymer) fabric. The same parameters were obtained with reference to specimens constituted by three layers of the same CFRP fabric and are also plotted in ESM Appendix A.

It can be noticed that differences between results on specimens with one or three layers of the same CFRP fabric are negligible. The mean values of $E$ calculated on the results of the groups B (1 layer) and A (3 layers) are the same (i.e., $256 \mathrm{GPa}$ ), while for $f_{\mathrm{tk}}$ the average values are 3125 and $3189 \mathrm{MPa}$ for 1 and 3 layers, respectively.

Such outcomes highlight that, for most products, both $E_{\mathrm{m}}$ and $f_{\mathrm{tk}}$ overcome the threshold values of the specific class. In particular, it is worth noting that the products with the highest values of the mean elastic modulus, i.e., greater than $250 \mathrm{MPa}$, cannot be classified according to class $350 / 1750$ or $350 / 2800$ since the threshold value $E_{\mathrm{m}}=350 \mathrm{MPa}$ is not reached, whereas the threshold values $f_{\text {tk }}=1750$ or $2800 \mathrm{MPa}$ are largely exceeded. These results evidence that either the class assignment criterion is not effective or that a new class, identified by an intermediate $E_{\mathrm{m}}$ threshold value (between 210 and $350 \mathrm{GPa}$ ), should be added.

\section{Effect of the adoption of classes}

In the following, an example of design of flexural strengthening for a simply supported reinforced concrete beam is described. The strengthening system is made of a cured-in situ CFRP system falling in class $210 \mathrm{C}$ and the resistant flexural moment of the strengthened section is calculated taking into account the design formulations given by the Italian guidelines [1] and the CNR document [3] for both intermediate and end debonding failure. According to these documents, the nominal values of the class $210 \mathrm{C}$, i.e., $E_{\mathrm{m}}=210,000 \mathrm{MPa}$ and $f_{\mathrm{tk}}=2700 \mathrm{MPa}$, must be adopted for the design.

A rectangular section with dimension $b=300 \mathrm{~mm}$ and $H=500 \mathrm{~mm}$ is considered. The internal steel reinforcement areas are 770 and $462 \mathrm{~mm}^{2}$ in tension and compression, respectively. The characteristic values of the concrete compressive strength and of the yielding stress of the steel reinforcement are assumed to be $f_{\mathrm{ck}}=20 \mathrm{MPa}$ and $f_{\mathrm{yk}}=450 \mathrm{MPa}$, respectively. Under these assumptions, the ultimate bending moment of the unstrengthened section is $M_{\text {unstr }}=128 \mathrm{kNm}$.

To strengthen the section, a cured-in situ CFRP strip is supposed to be applied along the whole width of the section, i.e., $b_{\mathrm{f}}=b=300 \mathrm{~mm}$ with equivalent thickness ${ }^{1} t_{\mathrm{f}}=0.164 \mathrm{~mm}$. As suggested by $[1,3]$ for a CFRP strengthening system operating in indoor conditions, the environmental factor $\eta_{a}=0.95$ is assumed, whereas the material safety factor is $\gamma_{\mathrm{f}}=1.10$ for controlled in situ applications. These assumptions lead to the following design tensile strain of the fibres for the reinforcement in tension failure:

$\varepsilon_{\mathrm{fd}}=\eta_{\mathrm{a}} \frac{f_{\mathrm{tk}} / E_{\mathrm{m}}}{\gamma_{\mathrm{f}}}=0.95 \frac{2,700 / 210,000}{1.10}=0.011$

In the most stressed section of the strengthened beam, the effective design strain of the strengthening system has to take into account also the intermediate debonding failure and, thus, the following limitation is assumed:

$\varepsilon_{\mathrm{fd}}=\min \left(\eta_{\mathrm{a}} \frac{\varepsilon_{\mathrm{fk}}}{\gamma_{\mathrm{f}}}, \varepsilon_{\mathrm{fdd}}\right)$

being $\varepsilon_{\mathrm{fdd}}$ the maximum strain associated with the intermediate debonding failure and calculated as follows:

$$
\begin{aligned}
\varepsilon_{\mathrm{fdd}} & =\frac{f_{\mathrm{fdd}, 2}}{E_{\mathrm{m}}} \\
f_{\mathrm{fdd}, 2} & =\frac{k_{\mathrm{q}}}{\gamma_{\mathrm{f}, \mathrm{d}}} \cdot \sqrt{\frac{E_{\mathrm{m}}}{t_{\mathrm{f}}} \cdot \frac{2 \cdot k_{\mathrm{b}} \cdot k_{\mathrm{G}, 2}}{\mathrm{FC}} \cdot \sqrt{f_{\mathrm{cm}} \cdot f_{\mathrm{ctm}}}}, \text { with } \\
k_{\mathrm{b}} & =\sqrt{\frac{2-\frac{b_{\mathrm{f}}}{b}}{1+\frac{b_{\mathrm{f}}}{b}} \geq 1}
\end{aligned}
$$

In Eq. (10), $k_{\mathrm{G}, 2}$ is a corrective factor based on experimental results and equal to $0.10 \mathrm{~mm}$ for every type of FRP reinforcement, $k_{\mathrm{q}}$ is a coefficient depending on the load pattern (1.25 for distributed load and 1.0 for other load configurations), $F C$ is the

\footnotetext{
${ }^{1}$ Thickness of an equivalent plate constituted only by the fibre material; it is the ratio between the weight per unit area of the dry fabric and the density of the fibre.
} 
'confidence' factor measuring the knowledge level of the structure, $f_{\mathrm{cm}}$ and $f_{\mathrm{ctm}}$ are the average values of compressive and tensile strength of concrete, respectively, and $\gamma_{\mathrm{f}, \mathrm{d}}$ is the partial safety factor of the reinforcement for debonding failure assumed equal to 1.2. For the case at hand, it is assumed $\mathrm{FC}=1$ and $k_{\mathrm{q}}=1$. The other symbols have the meaning already introduced.

Under these assumptions, one obtains $\varepsilon_{\text {fdd- }}$ $=0.0056$, lower than the design strain associated with the tension failure of the fibres and, therefore, it rules the strength capacity of the FRP strengthened section. The corresponding tensile stress in the CFRP reinforcement is $1182 \mathrm{MPa}$. The ultimate bending moment of the strengthened section is $157 \mathrm{kN} \mathrm{m}$, corresponding to an increment of the flexural capacity of $23 \%$ compared to the unstrengthened section.

With reference to the end debonding failure verifications, the maximum stress in the FRP reinforcement at the anchorage zone is calculated, according to $[1,3]$, as:

$f_{\mathrm{fdd}}=\frac{1}{\gamma_{\mathrm{f}, \mathrm{d}}} \cdot \sqrt{\frac{E_{\mathrm{m}}}{t_{\mathrm{f}}} \cdot \frac{2 \cdot k_{\mathrm{b}} \cdot k_{\mathrm{G}, 1}}{\mathrm{FC}} \cdot \sqrt{f_{\mathrm{cm}} \cdot f_{\mathrm{ctm}}}}$

where $k_{\mathrm{G}, 1}$ is a corrective factor calibrated on experimental results and equal to 0.037 for cured-in situ systems. The maximum stress turns out to be $f_{\text {fdd }}$ $=720 \mathrm{MPa}$.

The optimal bond length can also be calculated through the following equation:

$l_{\mathrm{fdd}}=\frac{\pi}{\gamma_{\mathrm{R}, \mathrm{d}}} \cdot \sqrt{\frac{E_{\mathrm{m}} \cdot t_{\mathrm{f}}}{8} \cdot s_{\mathrm{u}}^{2} \cdot \frac{\mathrm{FC}}{k_{\mathrm{b}} \cdot k_{\mathrm{G}, 1} \cdot \sqrt{f_{\mathrm{cm}} \cdot f_{\mathrm{ctm}}}}}$

where $\gamma_{R, d}$ is a safety factor for the model, assumed equal to 1.25 , and $s_{\mathrm{u}}=0.25 \mathrm{~mm}$ is the ultimate slip of the bond shear stress-slip law suggested by [3]. Equation (12) yields a values of $l_{\mathrm{fdd}}=76 \mathrm{~mm}$ for the bond length.

As already said, calculations above are made adopting the values of $E_{\mathrm{m}}$ and $f_{\mathrm{tk}}$ assigned to the class 210C. For the sake of example, in the same class, the tested product \#31 shows an average Young's modulus of 335,000 MPa, and a characteristic strength of $3251 \mathrm{MPa}$ (mean value minus 2 times the standard deviation of the set of 9 specimens). In the following, calculations are repeated adopting the actual values of modulus and strength.
In doing so, the design strain for tensile failure of fibres, $\varepsilon_{\mathrm{fd}}$, varies from 0.011 (class values) to 0.0084 (actual values), the maximum strain related to intermediate debonding failure in the most stressed section $\varepsilon_{\text {fdd }}$ varies from 0.0056 to 0.0045 , while the corresponding tensile stress in the CFRP reinforcement, $f_{\mathrm{dd}, 2}$, increases from 1182 to $1494 \mathrm{MPa}$ due to the higher value of the actual Young's modulus in comparison with the class value of $E_{\mathrm{m}}$. Thus, the inclusion of product \#31 in class 210C leads to underestimate the design value of the tensile stress in the CFRP reinforcement, $f_{\mathrm{dd}, 2}$, by about $20 \%$. Based on such a design stress, the ultimate bending moment of the strengthened section varies from 157 (class value) to $163 \mathrm{kNm}$ (actual value), demonstrating that the inclusion of product \#31 in the class $210 \mathrm{C}$ yields a slightly conservative value of the reinforced section moment capacity (about $-5 \%$ ).

With reference to the verification against the end debonding failure, the maximum stress in the reinforcement at the anchorage zone, $f_{\text {fdd }}$, varies from $720 \mathrm{MPa}$ to $909 \mathrm{MPa}$ when the actual value of $E_{\mathrm{m}}$ is considered. This means that, if the class values are used for the product \#31, a sensibly conservative prevision $(-25 \%)$ of the end-debonding stress in the CFRP reinforcement is obtained. Finally, the optimal bond length $l_{\mathrm{fdd}}$ varies from 76 to $96 \mathrm{~mm}$. Although such a result means a not conservative design when the class values are used, it is worth noting that the Italian guidelines provide a minimum optimal bond length of $200 \mathrm{~mm}$, which is quite larger than both the theoretical values.

\section{Conclusions}

A description of the experimental results obtained from the product qualification of many different FRP products yields a global perspective of mechanical parameters of the most common FRP systems adopted for structural repair and/or strengthening in the Italian national market. Qualification procedures, as well as the values of design parameters, are prescribed in a relevant Italian standard [10].

The examination of a wide database of wet-lay-up FRP products made of carbon sheets (30 different products), liable to fall in the $210 \mathrm{C}$ class provided by the Italian Guidelines on the qualification of FRP systems [10], allowed to carry out several statistical 
inquires. Such analyses proved that the 3-p Lognormal distribution is able to adequately describe the stochastic distribution of mechanical properties of the tested products, i.e., tensile strength and Young's modulus, mainly under standard environmental conditions. Also the stochastic distribution of the mechanical properties in case of several ageing effects (freeze/thaw cycles, humidity, saltwater, alkali environment) is well described by the 3-p Lognormal distribution. Only in case of freeze/thaw cycles, a slight difference between the experimental results and the probabilistic previsions given by the 3-p Lognormal distribution was observed.

The statistical and probabilistic analysis of the experimental data showed also that the Italian guidelines [1] provide an accurate evaluation of the partial factors, since the lowest suggested value, 1.10, exactly coincides with the strength partial factor related to the experimental data and the highest one, 1.25, leads to a more conservative design in order to take into account uncertainties related to operations on construction sites. Such a value is, however, not mentioned in the most recent version of the Italian document issued by CNR [3].

Conversely, the environmental conversion factors given by the Italian guidelines $(0.95,0.85$ and 0.85 for, respectively, indoor, outdoor and aggressive environments in the case of carbon fibres) are not conservative in some cases. The 5 th percentile values of tensile strength due to artificial ageing show, indeed, that an environmental conversion factor equal to 0.75 should be utilized for carbon fibres for the most common environmental conditionings (freeze/thaw, humidity, saltwater, alkali environment).

The need for a double series of experimental data on 1-ply and 3-ply specimens prescribed by the qualification guideline [10] does not correspond to any observed result, since the differences are negligible.

The conventional definition of the characteristic value (average value minus 2 times the standard deviation) appears to be too conservative in comparison with the experimental outcomes (i.e., the amplifying factor of standard deviation is 1.26 instead of 2).

Italian national standard requires all products to be categorized in a "class" and to consider the nominal values of the specified class for the Young's modulus and the characteristic strength for the structural design. By considering the classes defined by [10], such an approach turns out to be potentially not conservative in terms of bond length and conservative in terms of FRP stress both for intermediate and end debonding failure.

Finally, the examination of experimental results of similar CFRP products falling in the class 210C, evidenced that a new definition of classes, identified by an intermediate $E_{\mathrm{m}}$ threshold value (between 210 and $350 \mathrm{GPa}$ ), should be added. This result evidenced also that a review of the class assignment criteria is a needed step of the standard.

Future developments of the research will be aimed, indeed, to investigate the reliability of the other classes for both wet-lay-up and preformed FRP systems, to validate, as done for the class $210 \mathrm{C}$, the suggested values for partial and conversion factors and to assess the characteristic values of the tensile strength.

Finally, it is worth noting that, nevertheless the paper is focussed on a specific case regarding FRP materials, it can be considered exemplary of a problem, the technical assessment procedures for material properties aimed to material standardization, that can be generalized for many other products.

Acknowledgements This research study has been partially funded by the University of Naples "Parthenope" with a Grant within the call "Support for Individual Research for the 2015-17 Period" issued by Rectoral Decree No. 793/2017.

\section{Compliance with ethical standards}

Conflict of interest The authors declare that they have no conflict of interest.

Open Access This article is licensed under a Creative Commons Attribution 4.0 International License, which permits use, sharing, adaptation, distribution and reproduction in any medium or format, as long as you give appropriate credit to the original author(s) and the source, provide a link to the Creative Commons licence, and indicate if changes were made. The images or other third party material in this article are included in the article's Creative Commons licence, unless indicated otherwise in a credit line to the material. If material is not included in the article's Creative Commons licence and your intended use is not permitted by statutory regulation or exceeds the permitted use, you will need to obtain permission directly from the copyright holder. To view a copy of this licence, visit http://creativecommons.org/licenses/by/4.0/.

\section{References}

1. Linee guida per la Progettazione, l'Esecuzione ed il Collaudo di Interventi di Rinforzo di strutture di c.a., c.a.p. e 
murarie mediante FRP, Ministry of Infrastructure and Transportation (2009) (in Italian)

2. CNR DT 200 (2004) Guide for the design and construction of externally bonded FRP systems for strengthening existing structures. Advisory Committee on Technical Recommendation for Construction of National Research Council, Rome, Italy

3. CNR DT 200/R1 (2013) Guide for the design and construction of externally bonded FRP systems for strengthening existing structures. Advisory Committee on Technical Recommendation for Construction of National Research council, Rome, Italy

4. fib (2001) Externally bonded FRP reinforcement for RC structures. fib Bulletin 14, Technical Report, Task Group 9.3. FRP Reinforcement for Concrete Structures

5. De Lorenzis L, Miller B, Nanni A (2001) Bond of fiberreinforced polymer laminates to concrete. ACI Struct $\mathbf{J}$ 98(3):256-264

6. Teng JG, Chen JF, Smith ST, Lam L (2002) FRP strengthened RC structures. Wiley, London

7. Ceroni F, Pecce M (2004) Modelling of tension stiffening behaviour of RC ties strengthened with FRP sheets, ASCE. J Compos Constr 8(6):510-518

8. Barros JAO, Dias SJE, Lima JLT (2007) Efficacy of CFRPbased techniques for the flexural and shear strengthening of concrete beams. Cem Concr Compos 29(3):203-217

9. Ferracuti B, Savoia M, Mazzotti C (2007) Interface law for FRP-concrete delamination. Compos Struct 80(4):523-531

10. Linee Guida per la identificazione, la qualificazione ed il controllo di accettazione di compositi fibrorinforzati a matrice polimerica (FRP) da utilizzarsi per il consolidamento strutturale di costruzioni esistenti, Ministry of Infrastructure and Transportation (2019) (in Italian)

11. Jia J, Boothby TE, Bakis CE, Brown TL (2005) Durability evaluation of glass fiber reinforced-polymer-concrete bonded interfaces. J Compos Constr ASCE 9(4):348-358

12. Sciolti M, Frigione M, Aiello M (2010) Wet lay-up manufactured FRPs for concrete and masonry repair: influence of water on the properties of composites and on their epoxy components. J Compos Constr ASCE 14(6):823-833

13. Ghiassi B, Marcari G, Oliveira DV, Lourenço PB (2013) Water degrading effects on the bond behavior in FRPstrengthened masonry. Compos B 54:11-19
14. Ceroni F, Bonati A, Galimberti V, Occhiuzzi A (2018) Effects of environmental conditionings on the bond behavior of FRP and FRCM systems applied over concrete elements. J Eng Mech ASCE. https://doi.org/10.1061/ (ASCE)EM.1943-7889.0001375

15. Salzano P, Bonati A, Ceroni F, Crisci G, Franco A, Occhiuzzi A (2019) Statistical analysis on mechanical properties of FRP materials for structural strengthening. In: Papadrakakis M, Fragiadakis M (eds) Proceedings of the 7th ECCOMAS thematic conference on computational methods in structural dynamics and earthquake engineering, COMPDYN 2019, Crete, Greece, 24-26 June 2019

16. Weibull W (1951) A statistical distribution function of wide applicability. J Appl Mech 13:293-297

17. Padgett W, Durham S, Mason A (1995) Weibull analysis of the strength of carbon fibers using linear and power law models for the length effect. J Compos Mater 29:1873-1884

18. Hui C, Phoenix S, Shia D (1998) The single-filamentcomposite test: a new statistical theory for estimating the interfacial shear strength and Weibull parameters for fiber strength. Compos Sci Technol 57:1707-1725

19. Alqam M, Bennett RM, ZureickA -H (2002) Three-parameter vs. two-parameter Weibull distribution for pultruded composite material properties. Compos Struct 58:497-503

20. Sriramula S, Chryssanthopoulos MK (2009) Quantification of uncertainty modelling in stochastic analysis of FRP composites. Compos Part A 40:1673-1684

21. Lekou D, Philippidis T (2008) Mechanical property variability in FRP laminates and its effect on failure prediction. Compos Part B 39:1247-1256

22. https://www.spcforexcel.com/

23. Massey FJ (1951) The Kolmogorov-Smirnov test for goodness of fit. J Am Stat Assoc 46(2539):68-78

24. Lilliefors HW (1967) On the Kolmogorov-Smirnov test for normality with mean and variance unknown. J Am Stat Assoc 62(318):399-402

25. EN 1990:2002 (2002) Eurocode: basis of structural design, CEN

Publisher's Note Springer Nature remains neutral with regard to jurisdictional claims in published maps and institutional affiliations. 